\title{
Marcas do positivismo no governo municipal de Porto Alegre
}

\author{
MARGARET MARCHIORI BAKOS
}

$\mathrm{E}$ M UM CAPÍTULO de seu livro sobre a cultura brasileira vista pela ótica da crítica literária e da pesquisa histórica, Alfredo Bosi (1992) analisa como certos ideais positivistas constituíram a arqueologia da modernização brasileira. Em uma comunhão com os pressupostos desse autor, busco demonstrar que a influência do positivismo no Brasil não se esgotou com a vitória do regime republicano. Ao contrário, a partir de então, encontramos no Rio Grande do Sul, na prática política dos administradores do estado, um empenho extraordinário em governar a partir dos princípios desenvolvidos por Augusto Comte. Parafraseando Bosi, buscarei expor, neste artigo, como determinados ideais positivistas constituíram a arqueologia da modernização porto-alegrense, promovida sob os auspícios do governo do estado do Rio Grande do Sul.

Franco (1967) e Love (1975), entre outros, magistralmente analisaram o universo empírico, em que brilharam os próceres do Partido Republicano Riograndense (PRR): primeiramente Júlio de Castilhos e, depois, Borges de Medeiros, como governantes do Rio Grande do Sul.

O meu estudo privilegiou uma camada aparentemente menos profunda dessa realidade: o governo de Porto Alegre. Ao longo da República Velha e da Nova, aqui ocorreu um caso sui generis de continuísmo: de 1897 a 1937, por 40 anos, a cidade foi administrada por apenas três intendentes: José de Aguiar Montaury, Otávio Rocha e Alberto Bins.

Esse fenômeno político foi revelado pelo estudo como único e exemplar no Rio Grande do Sul, engendrando um cenário marcado por implicações ideológicas assaz significativas. É fato notório a grande influência da filosofia de Comte na formação do Partido Republicano Rio-grandense, quando o movimento positivista revestiu-se de cunho político e pragmático.

Segundo a idéia de que a história de uma cidade ou pequena região deve ser feita a partir da compreensão da realidade maior na qual se insere, relacionei a realidade municipal à regional - nesse período 1897 a 1937 - em pleno processo de desenvolvimento da produção capitalista. Porto Alegre foi considerada à época $a$ sala de visitas do Rio Grande do Sul, o que levou, por um lado, a modernizar e tornar aprazível a vivência na cidade e, por outro, a manter no governo pessoas da 
mais absoluta confiança do Partido Republicano Rio-grandense dispostas a encampar e a executar tais objetivos.

A expressão Porto Alegre - sala de visitas do Rio Grande do Sul começou a aparecer nos discursos dos representantes da cidade, a partir do final do século passado e ao longo da República Velha e da Nova. Para melhor entendê-la é necessário recorrer à filosofia positivista. Conforme esta ótica, Porto Alegre - como capital do estado - deveria passar uma imagem de ordem e de progresso, máxima que sintetiza a ideologia do Partido Republicano Rio-grandense (PRR), hoje imortalizada na bandeira do Brasil.

\section{Da intendência à prefeitura}

Entre 1890 e 1897 Porto Alegre possuiu sete chefes executivos. Três na qualidade de presidente da Junta Municipal, um administrador municipal, dois intendentes nomeados pelo governador e um eleito de forma indireta ( 1 ). Ao longo desse período ocorreram sérios casos de idiossincrasias entre intendentes de diferentes municípios e o presidente do estado, as quais eram muito mal vistas pelo castilhismo. A partir de então foram redobrados os cuidados na indicação de nomes para a chefia dos executivos municipais, na capital do estado, principalmente.

No caso de Porto Alegre, vale assinalar que a agremiação acertou nas escolhas, pois dessa data até 1937, ou seja, ao longo de 40 anos, Porto Alegre teve apenas três intendentes municipais. O primeiro permaneceu 27 anos no poder, o segundo faleceu no decorrer do seu mandato e o terceiro ficou quase dez anos no cargo.

A abordagem de como tal fato se deu impõe inicialmente uma rápida consideração sobre a ligação estrutural entre o ideário comteano e as medidas políticas ou administrativas tomadas pelos intendentes e demais autoridades rio-grandenses ao longo desse período.

A proclamação da República contribuiu para a polarização dos gaúchos em torno de dois partidos políticos bem organizados, entre os quais se instalou uma luta pelo poder. A filiação a um deles servia como o marco referencial mais importante para posicionar um homem no estado. Nesse aspecto, o Rio Grande do Sul diferiu de outras regiões brasileiras, onde os laços familiares eram, no mesmo sentido, fundamentais.

Havia os adeptos da União Nacional, que tinham em Silveira Martins o seu grande líder e que estabeleceriam, no futuro, as bases do Partido Federalista e do Libertador; e havia os republicanos, mormente castilhistas.

O grande número de membros que constituíam a União Nacional eram oriundos dos antigos partidos monárquicos, acolhendo também dissidentes do PRR. Esses, na sua maioria, afastaram-se do partido ou por discordância de Júlio de Castilhos ou pela crescente identificação que se instaurou entre a doutrina positivista e o programa partidário republicano. Suas tendências manifestaram-se 
desde os primórdios da organização do PRR na década de 80 , porém consolidaram-se e transpareceram com clareza na Constituição de 1891. A indicação de Castilhos para presidente do estado nesse mesmo ano e, posteriormente, em 1893 contribuiu para aumentar o descontentamento dos seus desafetos.

A Revolução Federalista de 1893, fazendo mais de dez mil vítimas nos 31 meses que perdurou, além de tornar-se tristemente famosa pelas violentas cenas de degola dos combatentes aprisionados por ambos os lados, foi o resultado cruento desse longo processo de idiossincrasias entre as duas principais agremiações partidárias.

A situação de violenta disputa pelo poder reverteu-se em 1896, quando à paz seguiu-se, no Rio Grande do Sul, a consolidação do PRR, simbolizada pela volta de Castilhos ao governo do estado. O projeto de governo definido pela agremiação tinha como base o ideário de Augusto Comte, porém com versão própria - o castilhismo. Entre as suas características mais importantes destacavam-se a presença dominadora do Poder Executivo e o seu comprometimento com o desenvolvimento capitalista.

Desde 1893, já então no poder, o Partido Republicano buscava manter a sua hegemonia recrutando, na sociedade civil, correligionários coniventes com o ideário castilhista para ocupar postos-chave no aparelho de estado.

O processo histórico de sucessão do chefe executivo municipal em Porto Alegre adquiriu características peculiares a partir de 1896, quando as indicações dos candidatos à intendência passaram a privilegiar o correligionário que demonstrasse total identificação com o castilhismo, o que implicava obediência cega ao líder do partido e ao presidente do estado, as figuras mais representativas do PRR.

A primeira Constituição Republicana do estado - 1891 -, que teve Júlio de Castilhos como seu principal mentor, fornecia os meios técnicos necessários para o governo do estado controlar os municípios apesar de, em leitura menos avisada, ela parecesse assegurar a autonomia municipal. A primeira instância da lealdade política eram os próprios critérios de indicação do intendente; a segunda era a maneira como se fazia sua efetivação no poder - quando prestava compromisso formal de fidelidade para com o PRR e o seu líder mais expressivo, o presidente do estado, e quando recebia dele o apoio para o seu exercício administrativo: chave do continuísmo. Se ele servisse com fidelidade, perpetuava-se no cargo, fato explicado pelo princípio castilhista de que o poder vinha do saber. Tal premissa justificava a permanência de um político em um mesmo posto por um longo período de tempo, a fim de que conhecesse todos os macetes de sua função.

A rara situação de continuísmo político que se observava no governo de Porto Alegre, em nível de capital de estado, ao contrário de outras importantes cidades do país, no Rio Grande do Sul era também única em nível de município.

A situação era representativa, por um lado, da força do PRR no estado para impor essa política e, por outro, da preocupação partidária em ter à testa do gover- 
no de Porto Alegre um elemento de sua mais absoluta confiança. A permanência no governo de Porto Alegre - ao longo de 40 anos - de chefes municipais apontados pela cúpula do PRR para ocupar o posto, pode se tornar mais compreensível à luz dos fundamentos teóricos de Antonio Gramsci, quando ele demonstra a possibilidade de serem conseguidos o equilíbrio e a arbitragem entre os interesses de um grupo e de outros, aos quais ele se propõe cooptar (Gramsci, 1980:22). No caso, foram a proposta modernizadora do PRR e o seu objetivo de promover o desenvolvimento do capitalismo regional que beneficiaram muitos setores da economia sul-riograndense, possibilitando-lhe conquistar a hegemonia política estadual.

\section{Indicação e posse dos edis do continuísmo}

O continuísmo no governo municipal de Porto Alegre iniciou-se com a indicação de José de Aguiar Montaury, por Júlio de Castilhos, em 1896. Eleito no mesmo ano, Montaury assumiu efetivamente o governo da cidade em 1897, permanecendo 27 anos na função.

Montaury nasceu no Rio de Janeiro, em 1858. Formou-se em engenharia pela Escola Politécnica, onde recebeu grande influência da filosofia positivista. Tal aspecto facilitou-lhe ser bem aceito no Rio Grande do Sul, atuando, conforme preceitos do PRR, como funcionário federal da Comissão de Terras e Estabelecimento de Imigrantes no estado.

A partir de então, e a cada renovação de seu mandato, Montaury confirmou sua obediência e devotamento ao PRR, a Júlio de Castilhos e, posteriormente, a Borges de Medeiros: "Suprindo pela lealdade e pelos esforços o que me faltava em competência, procurei corresponder a confiança que me havia sido dispensada; e graças à coadjuvação patriótica do Conselho Municipal, à colaboração dos meus companheiros de trabalho e auxílio da generosa população, o Benemérito Dr. Júlio de Castilhos, findo o mandato, renovou a imerecida distinção que me conferira, julgando necessária a continuidade no cargo, indicando-me para o quatriênio que hoje finda" (2).

Montaury foi o primeiro intendente a governar consoante os princípios da $1^{\text {a }}$ Lei Orgânica Municipal de 1892. A lei estabelecia o território do município, sua divisão em distritos e comissariados, suas rendas, taxas e atribuições. Estipulava igualmente que o governo municipal deveria ser exercido por um intendente - com poderes para dirigir todos os serviços - e por um Conselho - em lugar da antiga Assembléia Municipal.

O Conselho reunia-se apenas dois meses por ano para a votação de questões relativas ao orçamento municipal. As leis, decretos e atos eram feitos pelo intendente. A situação, afirma Spalding (1967:157), tornou o intendente a única cabeça pensante, depois do presidente do estado. Todos os cargos eram eletivos e renováveis a cada quatro anos em pleitos de voto aberto. $\mathrm{O}$ intendente podia escolher apenas o vice e os subintendentes para quantos distritos houvesse no município. 
Em 1898, um ano após o início do mandato de Aguiar, encerrou-se o período instável e de legitimação progressiva da República positivista. A Borges de Medeiros, pupilo dileto e sucessor de Júlio de Castilhos, coube consolidar definitivamente a República (Trindade, 1979:146).

Entre as medidas por ele tomadas, interessam a este trabalho as modificações que Borges introduziu na Lei Orgânica de Porto Alegre. Em 1902, reduzindo de forma drástica o poder do intendente, alterou a sua faculdade de propor reformas à Lei Orgânica, as quais somente seriam levadas em consideração se aprovadas pela totalidade dos membros do Conselho. A lei também definiu critérios mais rigorosos para o preenchimento de cargos, como o de vice-intendente, que não poderia pertencer, até o décimo grau de parentesco, à família do intendente (3).

Em 1903, com a morte de Júlio de Castilhos, Borges assumiu cumulativamente a direção do governo e do partido. Desde então, e até 1923, ele rotineiramente indicou a José de Aguiar Montaury para a intendência de Porto Alegre. Uma faceta de seu discurso para justificar o continuísmo foi a capacidade de Montaury de administrar o municipio às claras, de minorar as condições de vida dos pobres e de refrear a ganância dos capitalistas: três ideais comteanos. Na busca da paz social, segundo o ideário castilhista, era necessário essa integração do proletariado à sociedade, por meio de concessões dos privilegiados. Cabia ao estado forte tal mediação, pois evitaria conflitos entre as classes e promoveria o progresso geral.

A Federação, órgão da imprensa criado e voltado para prestigiar o grupo e as iniciativas do PRR, publicou sempre, ao longo das várias gestões de Montaury, artigos e dados apontando o apoio que os operários davam às mesmas. Tal postura era denegrida em outras folhas diárias que, em flagrante oposição ao periódico do governo, denunciavam o empobrecimento da população porto-alegrense e faziam graves acusações à política do PRR.

A conhecida luta fraticida de 1923 ocorrida no Rio Grande do Sul, tal como a de 1893, foi banhada pelo sangue jorrado nos inúmeros episódios de degola, patrocinados tanto pela Aliança Libertadora quanto pelo Partido Republicano Riograndense. Teve o seu final com o Pacto de Pedras Altas, sem dúvida um episódio altamente representativo do declínio da hegemonia do PRR no estado.

Como no decorrer da campanha contra a quinta reeleição de Borges a critica fincou pé no continuísmo que o PRR propiciava aos seus mandatários e na sua repercussão na economia dos municípios e de todo o estado, a permanência foi o primeiro dos artigos a ser modificado em Pedras Altas na Constituição Estadual e nas Leis Orgânicas Municipais. Pela nova legislação, o intendente não poderia mais ser reeleito para o quatriênio imediato.

Dessa forma, em 1924 foi impedida a reeleição de Montaury ao governo de Porto Alegre. Consoante João Neves da Fontoura, republicano positivista engajado e amigo pessoal de Montaury, a nova lei trouxe aos porto-alegrenses um coro de esperanças de reformas e de progressos. Neves da Fontoura explicou que havia 
uma lastimável contradição entre as simpatias que a pessoa do intendente despertava e o descontentamento com a sua administração. $\mathrm{O}$ horror às mudanças que transpareceu ao longo das administrações de Montaury contribuiu, conforme seu correligionário, para criar uma atmosfera de impopularidade em torno do partido e do governo.

Para suceder a José Montaury de Aguiar Leitão, o PRR, por escolha de Borges de Medeiros, indicou Otávio Rocha como intendente de Porto Alegre e Alberto Bins para vice-intendente.

Otávio Rocha, gaúcho de Pelotas, engenheiro, 47 anos, metade dos quais dedicada à política partidária, foi colaborador do Diário Popular, em Pelotas, diretor de A Federação de Porto Alegre, Secretário da Fazenda do estado, deputado federal, membro da Comissão de Finanças e líder das bancadas republicanas do Rio Grande do Sul, da Bahia, do Rio de Janeiro e de Pernambuco. Além de todas essas credenciais, Otávio Rocha era ainda o discípulo predileto de Borges de Medeiros (Ferreira, 1961:1).

O candidato recebeu apoio do comércio e da indústria de Porto Alegre, além da adesão imediata da Liga dos Operários Republicanos do Rio Grande do Sul.

A Federação explorou o fato, mostrando ser o voto aberto dos republicanos mais honesto que o secreto propugnado pela Aliança Libertadora, posição essa, segundo o jornal, reveladora do medo de assumir posição e de viver às claras, como propugnava a ideologia castilhista.

Enquanto a candidatura de Otávio Rocha foi aceita sem contestação entre os seus correligionários, a de Bins atraiu algumas críticas. Essas não diziam respeito à sua pessoa, mas se originavam de um memorial que a colônia teutônica teria dirigido a Borges de Medeiros solicitando representação à parte na Câmara Federal pelo partido situacionista, indicando Alberto Bins às eleições municipais.

Conforme $O$ Exemplo, essa era uma aspiração descabida da colônia alemã. Caso fosse aceita pelo presidente do estado, poderia gerar precedente para futuras petições das comunidades francesa, inglesa e espanhola, entre outras, que estariam assim favorecendo a criação de facções dentro do governo e de candidatos de grupos.

É importante esclarecer que $O$ Exemplo foi um jornal criado e dirigido por negros, identificados com as premissas ideológicas positivistas do PRR, principalmente no que se referiam à igualdade das raças, à condenação da discriminação e à valorização das características peculiares a cada grupo étnico. No caso da raça negra, destacavam a sua superioridade afetiva, fato que poderia explicar os porquês da sua sujeição ao longo dos séculos de opressão escravagista (Bakos, 1982:154).

$\mathrm{O}$ firme apoio de Borges à candidatura de Bins ao posto de vice-intendente parece ter minimizado o teor do discurso de O Exemplo, pois o líder republicano 
apelou para a necessidade de integração entre o proletariado e as lideranças regionais. Bins era um homem inegavelmente bem sucedido nos negócios, fato usado com habilidade na sua campanha como argumento de garantia para o progresso de Porto Alegre.

Rocha iniciou seu governo em um momento de grave crise nacional, que atingia também o Rio Grande do Sul. Confessou-se pouco qualificado para o cargo administrativo, pois sempre trabalhara como político e, como tal, comprometeu-se a seguir um programa partidário e não-pessoal, obedecendo ao lema positivista de conservar melhorando e prometendo obediência a Borges de Medeiros como chefe de seu partido: "Antes de organizar o nosso programa, trocamos idéias com o chefe do Partido Republicano Rio-grandense, que dá a todos os seus partidários orientação política e administrativa (4).

Na eleição para a sucessão municipal de Porto Alegre de 1928 o continuísmo prosseguiu, com a indicação - pelo PRR - de Alberto Bins para intendente da capital, em um pleito sem concorrentes. Os libertadores, depois de lançarem candidatos para os cargos de intendente e vice-intendente de Porto Alegre, decidiram não concorrer, retirando suas chapas.

As razões para a escolha de Bins foram as mesmas que, quatro anos antes, $\mathrm{O}$ guindaram à vice-intendência no governo de Otávio Rocha: sua dedicação ao PRR, sua militância político-partidária como vereador, conselheiro e deputado estadual, e o fato de ser um capitalista vencedor.

Porto-alegrense, nascido em 1869, estudou na Inglaterra e na Alemanha, de onde trouxe idéias novas, especialmente no ramo da indústria metalúrgica.

Ser um homem rico, muito bem relacionado, viajado, levou-o a atitudes de maior independência, se comparado a Montaury e a Otávio Rocha com relação à maior autoridade política no estado. Certa feita, após a Revolução de 30, sendo interventor no Rio Grande do Sul Flores da Cunha, Bins desapontou-se com a sua interferência nos assuntos municipais e declarou-se disposto a renunciar ao cargo. São suas palavras: "Se o senhor não me quiser mais como prefeito de Porto Alegre, então volto à fábrica de cofres" (Fausel, s/d.:9).

Essa renúncia, entretanto, nunca se concretizou. Bins costumava apoiar a Flores da Cunha, inclusive na criação, pelo mesmo, do Partido Republicano Liberal, em 1932. A influência recíproca entre o presidente do estado e os intendentes, característica em Porto Alegre, ao longo da República Velha, parece ter persistido após 30. Em 1933, Bins foi felicitado por Flores da Cunha pela sua administração na prefeitura durante o período de 1923-1933, julgada como brilhante pelo interventor.

Bins dizia-se, por um lado, representante das classes produtoras por ter participado, em 1926, da fundação do Sindicato do Arroz e, em 1927, da Varig, primeira empresa aérea comercial a funcionar no país, além de ter sido presidente da Associação Comercial de Porto Alegre e responsável por indústrias importantes no 
estado, como a União de Ferros, Cofres Berta, entre outras. Por outro, propunhase a amparar os operários, fundando em 1930 um Comitê com essa finalidade, ao mesmo tempo em que instituía sindicatos de apoio aos industriais. Segundo Love (1975), o talento de Bins na organização de sindicatos e a cobertura de Getúlio às atividades da pecuária contribuíram para melhorar as relações do PRR com o partido da oposição.

Sempre reconduzido por Flores da Cunha, Bins enfrentou, entretanto, situação muito diferente daquelas com que lidaram os seus antecessores no cargo. Getúlio Vargas, desde 1930, quietamente, foi construindo em nível de país, o que Júlio de Castilhos e Borges de Medeiros realizaram no Rio Grande do Sul: uma Constituição centralizadora e um Poder Executivo forte. A Constituição de 1934 secundou, em parte, essa diretriz anti-oligárquica ao limitar a competência dos estados junto aos seus municípios, na tentativa de evitar que estes se tornassem novamente armas políticas poderosas das oligarquias. Com a discriminação de rendas do município passando, a partir daí, a ser matéria da Constituição Federal, o fato constituiu importante freio às autonomias municipais.

Getúlio, certamente, sabia da importância do exercício político na instância municipal. Segundo o positivismo, o município funciona como a escola primária da democracia, onde nascem e vivem os elementos geradores dos movimentos sociais e políticos, o que o torna uma espécie de matriz das novas lideranças.

A oposição entre o presidente do governo provisório e o interventor gaúcho, que se manifestava contrário já às primeiras medidas restritivas à liberdade dos governos estaduais, atingiu o seu clímax em 1935. Nesse ano, Getúlio Vargas visitou Porto Alegre por ocasião das festas em comemoração ao centenário da Revolução Farroupilha. Segundo Cortês (1974:66), inicialmente eles agiram como amigos cautelosos, mas uma semana depois já atuavam como inimigos não-declarados.

Sob a pressão de uma possível intervenção armada federal no Sul, realizou-se o $3^{\circ}$ Congresso do Partido Republicano Liberal, com um grande lema a ser defendido: Os rio-grandenses sempre tiveram repugnância e ojeriza ao arbitrio è prepotência.

Tratava-se de delicada fase da História do PRR: a do enfrentamento entre dois de seus grandes líderes: Getúlio Vargas e Flores da Cunha. A desunião da Frente Única Gaúcha em torno dessa disputa, principalmente, facilitou a consecução dos planos getulistas de intervir no estado. Flores da Cunha escapou para Montevidéu onde, sob a vigilância de Baptista Luzardo, nomeado para embaixador brasileiro naquele país, não pode exercer livremente oposição ao presidente do Brasil.

Em novembro de 1937 Alberto Bins enviou um telegrama a Getúlio Vargas, no qual anunciava seu afastamento do Partido Republicano Liberal e da vida política. Confessava ter lido com mais atenção a Constituição do Estado Novo e, finalmente, compreendido que o caminho escolhido por Getúlio era o único compatível com o nosso meio, no qual a má política tinha conduzido à desagregação das forças vivas da nação (Bakos, 1996:72). 
A declaração de solidariedade de Bins ao Estado Novo, no entanto, não the poupou perseguições pessoais por parte dos próximos líderes que o sucederam nos postos-chave do governo municipal. A sua atuação como prefeito ligava-o irremediavelmente à política castilhista que, segundo Borges de Medeiros, chegava ao fim com o Decreto do Estado Novo. Ao ser argüido por um repórter a respeito de Getúlio Vargas, Borges respondeu secamente: "Este homem foi o coveiro do Partido Republicano" (Araújo, 1985:202).

Borges até poderia ter perdoado a Flores da Cunha por tê-lo mandado prender em 1932, pois Flores era discípulo de Pinheiro Machado, "mas o crime perpetrado por Vargas, o seu discípulo predileto, extinguindo os partidos, em 1937, inclusive o Partido Republicano, ferira-o como uma amputação" (Araújo, 1985:202).

Em 1937, a designação de novo prefeito teve significado fundamental: pôs um fim ao continuísmo do PRR e à sua política administrativa. Entre as primeiras medidas do novo edil, ocorreu a negativa ao pedido de moratória, feito por expressiva parcela da população de Porto Alegre ao Conselho Municipal, relativa ao pagamento de suas dívidas para com os serviços públicos. Até esse momento, Bins e o Conselho optavam pela medida de tolerância, argumentando que, desse modo, os resultados infalíveis, matemáticos, positivos, que ensinava a economia política, trariam, em conseqüência, uma época de prosperidade para o Rio Grande do Sul. Tal discurso sintetizava a ideologia e a práxis da política econômica do órgão consultivo da administração pública municipal de Porto Alegre ao longo de quatro décadas, que ora findava.

\section{As práticas continuístas}

Pudemos facilmente identificar o continuísmo, manobra política tendente a manter no poder uma pessoa ou um grupo, como uma prática da doutrina castilhista, ao longo de 40 anos no governo de Porto Alegre. A mesma singeleza não ocorre quando se busca analisar as práticas desses edis com relação à doutrina políticopartidária. Certamente também houve aspectos de caráter contínuo na administração de Montaury, Rocha e Bins, pois atuaram na mesma realidade concreta: o município de Porto Alegre. É mister frisar, entretanto, ser a busca das semelhanças, no fazer histórico, menos importante que a das diferenças e do entendimento do porquê elas se processaram, pois as necessidades e os valores das pessoas mudam ao longo dos tempos, fato que os três chefes pressentiram, como analistas políticos, vivenciaram e tentaram administrar nos seus respectivos períodos de mandato.

Partindo do fato de que as vias política e burocrática ofereceram, ao longo de 40 anos, facilidades inusitadas à cúpula do PRR para atender aos seus correligionários, de um simples fenômeno de estratégia política, o continuismo tornou-se um viés fundamental para resgatar o tipo de relação existente entre as práticas administrativas continuístas, o atendimento aos interesses dos produtores e as condições de governabilidade de Porto Alegre, sob a égide castilhista. 
Entre as inúmeras características da política administrativa rumo à ordem e ao progresso, três fundamentais podem ser apontadas: municipalizar os serviços públicos, evitar contrair dívidas públicas e integrar o proletariado à sociedade de classes.

\section{Municipalizar os serviços públicos}

Procedimento que visava a atingir um maior número de pessoas. Na perseguição desse objetivo, o governo de Porto Alegre municipalizou os serviços de água, esgotos, iluminação, tráfego, policiamento, instrução, higiene alimentar, limpeza, asseio e assistência pública, tendo mais serviços ao seu encargo que todas as outras grandes capitais de estado do país, como São Paulo, Rio de Janeiro e Belo Horizonte.

\section{Evitar contrair dívidas públicas}

Exceto se tais dívidas fossem necessárias para dar uma feição mais moderna à cidade. Com essa justificativa, o governo municipal de Porto Alegre contraiu quatro grandes empréstimos no exterior:

- em 1909 - 600.000 libras, com banqueiros de Londres para amortização em 15 anos;

- em 1922 - US\$3.500.000, com banqueiros norte-americanos para amortização em 15 anos;

- em 1926 - US\$ 4.000.000, com banqueiros norte-americanos, sendo surpreendente nesse caso que a garantia do empréstimo fossem todas as rendas do município;

- em 1928 - US\$ 2.250.000, com o Bank of London, Banco Brasileiro-alemão, Banco Francês-italiano, Banco Pelotense, Banco Pfeiffer, British Bank, governo do estado do Rio Grande do Sul e ainda instituições da praça do Rio de Janeiro. Grande parte desse empréstimo foi empregada para amortizar o empréstimo de 1922. O restante líquido foi empregado nos serviços de água, de esgotos, de calçamento, de energia elétrica e na remodelação da cidade, como a construção de grandes avenidas, entre elas a que leva o sugestivo nome de Júlio de Castilhos, considerado o mais importante entre os fundadores do PRR.

Além de endividado pelos empréstimos, o erário municipal passou a arcar também com as despesas criadas pela contratação de centenas de novos funcionários. Se por um lado, alguns eram realmente necessários em face das novas funções assumidas pela municipalização dos serviços essenciais, por outro, muitos dos novos funcionários eram chamados de deputados da limpeza pública, cognome oriundo da malícia popular, em sugestiva alusão ao fato de que tais funcionários recebiam honoris causa e não pro-labore. 


\section{Integrar o proletariado à sociedade de classes}

Tal fato implicava seu acesso à moradia própria, higiênica e confortável. A inconsistência desse projeto de governo pode ser apreendida de imediato: por um lado, o PRR propunha facilitar o acesso à moradia de toda a população, eliminando todos os cortiços que enfeiavam Porto Alegre; por outro, entretanto, a administração pública municipal inviabilizava essa nova ordem na medida que favorecia a privatização do solo urbano.

Dediquei atenção especial, nesta pesquisa, ao estudo da questão habitação em Porto Alegre, para desvelar como, mediante regulamentos, tributações e investimentos públicos, o poder municipal de Porto Alegre participou do desenvolvimento da cidade.

Ficam evidentes as incongruências entre a filosofia política castilhista e as práticas administrativas, se atentarmos para algumas de suas medidas que foram levantadas ao longo da investigação:

- determinação das áreas da cidade onde deveriam ser implantados os serviços públicos básicos e o encarecimento dos tributos cobrados pelo seu uso, provocando o afastamento de pessoas sem recursos dessas zonas, privilegiadas para outras, nas quais, além de ficarem longe dos seus locais de trabalho, gastando quase o seu salário no transporte diário, ainda tinham de pagar pelos custos da modernização da cidade sem dela tirar proveito;

- permissão, sem ônus, dos investimentos capitalistas no solo urbano, facilitando a permanência de extensas áreas de terrenos baldios, o que diminuía a arrecadação de impostos, prejudicando a implantação dos serviços básicos. Apenas em 1927 começou a tributação sobre terrenos baldios em Porto Alegre;

- aprovação de medidas paliativas para resolver o problema habitacional, tais como as altas percentagens cobradas sobre os cortiços da cidade, com a justificativa de que a intenção era obrigar os capitalistas a construírem moradias mais adequadas para aluguel. Tais aumentos eram, sabidamente, repassados pelos proprietários aos seus inquilinos e as habitações adequadas aos bolsos das famílias de baixa renda jamais foram construídas;

- prorrogação por tempo indefinido das construções de vilas populares pelo governo, mesmo tendo à sua disposição áreas específicas como Navegantes, São João e da Redenção, destinadas mais tarde a outros fins;

- estabelecimento de padrões estéticos que onerariam demasiadamente as novas edificações a serem realizadas, as quais, providas de serviços básicos, constituiriam obras fundamentais para dar uma imagem progressista à cidade, servindo como uma das estratégias de interesse político do continuísmo. 
Assim, o estudo da questão habitacional em Porto Alegre foi importante para configurar a continuidade na política do governo da cidade.

À guisa de conclusão, é mister reforçar a ligação estrutural entre o ideário comteano (via Castilhos) e as medidas político-administrativas tomadas pelos intendentes e demais autoridades rio-grandenses ao longo da República Velha e da Nova.

Tal ligação apareceu nas medidas para reforçar a prestação de serviços públicos básicos, os quais, entretanto, não beneficiaram diretamente toda a população, que, em contrapartida, repartiu seus custos. O governo municipal endividou-se interna e externamente.

Em 1937, Alberto Bins, às vésperas de ser afastado do governo de Porto Alegre pelo golpe do Estado Novo, confessou a Flores da Cunha, interventor no estado, que 20 mil contribuintes tinham solicitado moratória à Câmara Municipal. Nas palavras de Bins, "a cidade de Porto Alegre estava ingovernável".

É importante lembrar ainda que, compondo os grupos de liderança, havia pessoas com visões de mundo desiguais em cargos públicos. No pano de fundo da política rio-grandense ao longo do período em estudo - 1897-1937 -, havia o continuísmo do PRR: na superfície atuavam homens, em muito ou nada identificados com ele, todos partícipes desse processo histórico de Porto Alegre.

Talvez a mais importante das contribuições de uma análise histórica dessa natureza seja a impossibilidade de homogeneizar os homens e os processos históricos, cuja apreensão tende, ao contrário, a nos mostrar suas diferenças. $\mathrm{O}$ fazer histórico, em lugar de confirmar nossa compreensão de uma época, pode transformála e aos nossos preconceitos.

Da administração de José Montaury à de Alberto Bins, passando pelo período de Otávio Rocha, até à atualidade, pouco a pouco Porto Alegre foi inchando. De uma cidade-aldeia, como a classificava Borges de Medeiros na virada do século, tornou-se uma cidade populosa e multiplicou sua área de ocupação, o que tornou quase inexistente as fronteiras com os municípios limítrofes.

Quem conhece Porto Alegre está familiarizado com os nomes de Júlio de Castilhos, Borges de Medeiros, José Montaury, Otávio Rocha e Alberto Bins, porque tais nomes indicam algumas das avenidas mais importantes da cidade. Poucos relacionam esses personagens com a História de Porto Alegre, muitos nem cogitam saber por que eles foram eternizados nas placas que referem artérias desse espaço humano.

Essa ignorância veio junto com a perda do nosso sentido de historicidade, tanto de nossos referenciais particulares - quem eu sou, de onde venho e para onde vou - quanto dos sociais - o conhecimento e o exercício dos direitos e dos deveres inerentes à cidadania. Ela explica como, ao longo dos anos, tantos edis atentaram tão pouco para os problemas estruturais de Porto Alegre, mas, ao contrário, con- 
tribuíram, descuidadamente ou guindados por interesses próprios ou de grupos de pressão, para torná-la pior que a área de serviço de uma casa modesta e bastante diferente do que seria uma sala de visitas da burguesia, como fora planejado na época da proclamação da República no país.

\section{Notas}

1 Anais do AHMPOA, 1983, p. 51.

2 Relatório, 1905, p. 3.

3 Decreto n 471.

4 Relatório, 1927, p. 3.

Referências bibliográficas:

ANTONACCI, M.A. RS: as aposições e a revolução de 1923. Porto Alegre, Mercado Aberto, 1981.

ARAÚJO, Rubens. Os Vargas. Porto Alegre, 1985.

BAKOS, Margaret M. O continuísmo administrativo no governo municipal de Porto Alegre: 1897-1937. Revista de Estudos Ibero-americanos, v. XIII, n. 2, p. 161-194, dez. 1987.

A habitação em Porto Alegre: problemas e projetos administrativos (1897-1937). Cadernos de Estudo, n.l. Porto Alegre, UFRGS Curso de Pós-graduação em História, 1988.

Municipalização e endividamento. In: WEIMER, G. (org.). Urbanismo no Rio Grande do Sul. Porto Alegre, Ed. da UFRGS, 1992.

Decorando a sala de visitas: Porto Alegre na virada do século 19. In.: MAUCH, Claudia (org.). Porto Alegre, na virada do século XIX. Porto Alegre, Ed. da UFRGS, 1994.

BOSI, Alfredo. Dialética da colonização. São Paulo, Companhia das Letras, 1992.

CORTÊS, Carlos. Gaucho politics in Brazil. México, University of New Mexico Press, 1974.

ESCOBAR, W. Apontamentos para a história da revolução de 1893. Porto Alegre, Globo, 1929.

FAUSEL, Erich. Alberto Bins. O merlense brasileiro. São Leopoldo, Rotermund, s/d.

FERREIRA, F. Arthur. História Geral do Rio Grande do Sul. Porto Alegre, Globo, 1958.

FRANCO, Sérgio da Costa. Júlio de Castilhos e sua época. Porto Alegre, Globo, 1967. 
GRAMSCI, Antonio. Maquiavel, a politica e o Estado moderno. Rio de Janeiro, Civilização Brasileira, 1980.

LOVE, Joseph. O regionalismo gaúcho. São Paulo, Perspectiva, 1975.

PESAVENTO, Sandra. História do Rio Grande do Sul. Porto Alegre, Mercado Aberto, 1982.

RODRIGUEZ, Ricardo V. Castilhismo, uma filosofia da República. Caxias do Sul, UCS, 1980.

SPALDING, Walter. Pequena História de Porto Alegre. Porto Alegre, Sulina, 1967.

TRINDADE, Hélgio (org.). Poder legislativo e autoritarismo no Rio Grande do Sul, 1891-1937. Porto Alegre, Sulina, 1980.

RESUMO - NESTE ARTIGO são examinadas as tendências teóricas dos políticos do Partido Republicano Rio-grandense, que têm por base o positivismo de Augusto Comte. Entre os princípios mais importantes, por eles observados, estava o do continuísmo político. Isto pode elucidar o fato de que, ao longo dos 40 anos de hegemonia política do PRR - de 1897 a 1937 -, Porto Alegre, capital do estado, teve apenas três intendentes.

ABSTRACT - IN THIS ARTICLE is examined the theoretical set developed by the politicians of the Republican Party of Rio Grande do Sul, which were based on August Comte's positivism. Among the more important principles, observed by them, was the political trend. This can elucidate the fact that during the 40 years of the political hegemony of the PRR - from 1897 to 1937 -, Porto Alegre, the capital of the state, had only three quartmasters.

Margaret Marchiori Bakos é doutora em História pela USP, professora da Pontifícia Universidade Católica do Rio Grande do Sul e autora, entre outros, de dois livros especialmente dedicados ao estudo da ligação estrutural entre o ideário comteano (via Castilhos) e as medidas políticas ou administrativas tomadas pelos intendentes e demais autoridades rio-grandenses dos finais do século XIX e ao longo da República Velha: RS: escravismo e abolição (Porto Alegre, Mercado Aberto, 1982) e Porto Alegre e seus eternos intendentes (Porto Alegre, EdiPuc, 1986). 